\title{
TTK activates Akt and promotes proliferation and migration of hepatocellular carcinoma cells
}

\author{
Xing Liu ${ }^{1,2}$, Weijia Liao ${ }^{4}$, Qing Yuan ${ }^{1}$, Ying $\mathrm{Ou}^{1}$, Jian Huang ${ }^{1,2,3}$ \\ ${ }^{1}$ National Engineering Center for Biochip at Shanghai, Shanghai, China \\ ${ }^{2}$ Shanghai-MOST Key Laboratory for Disease and Health Genomics, Chinese National Human Genome Center at Shanghai, \\ Shanghai, China \\ ${ }^{3}$ Key Laboratory of Systems Biomedicine (Ministry of Education) and Collaborative Innovation Center of Systems Biomedicine, \\ Shanghai Center for Systems Biomedicine, Shanghai Jiao Tong University, Shanghai, China \\ ${ }^{4}$ Hepatology Institute of Guilin Medical University, Guilin, Guangxi Zhuang Autonomous Region, China \\ Correspondence to: \\ Jian Huang, e-mail: huangjchgc@hotmail.com \\ Xing Liu, e-mail: liuxing118@aliyun.com \\ Keywords: hepatocarcinogenesis, TTK gene, cell migration, demethylation, AKt \\ Received: April 19, $2015 \quad$ Accepted: September 07, 2015 Published: September 19, 2015
}

\section{ABSTRACT}

Hepatocellular carcinoma (HCC) is one of the most malignant cancers with poor clinical outcome. The protein kinase human monopolar spindle 1 (hMps1/TTK) gene expression is significantly increased in HCCs. However, its contributions to hepatocarcinogenesis remain unclear. In this study, we found that TTK was overexpressed in $77.63 \%(118 / 152)$ HCC specimens. Elevated TTK expression positively correlated with large tumor size and presence of the portal vein tumor thrombus (PVTT). Demethylation in its promoter increased TTK expression in HCC. In vitro assays revealed that TTK not only promoted cell proliferation and anchorage-independent growth, but also cell migration. Subsequent investigations revealed that TTK activated Akt/mTOR pathway in a p53 dependent manner. We also found that TTK specific kinase inhibitor AZ3146 could decrease HCC cell growth. In conclusion, TTK contributes to HCC tumorigenesis via promoting cell proliferation and migration. It may serve as a novel biomarker and a potential target in HCC cancer therapy.

\section{INTRODUCTION}

Hepatocellular carcinoma (HCC) is one of the most malignant tumor worldwide, causing more than 746,000 deaths per year (http://globocan.iarc.fr/Pages/ fact_sheets_cancer.aspx). Conventional clinical and pathological indexes are used in adjudgement of HCC stages and outcomes but limited with low accuracy. The molecular mechanism of HCC carcinogenesis still remains unclear [1]. Thus, it is important to seek novel biomarkers and molecular targets of HCC.

Protein kinases comprise enzymes with catalytic activity and transduces functional signalings as key regulators of critical cellular processes [2]. Dysregulation of kinases in tumors contribute to carcinogenesis and is associated with tumor progression and clinical outcome [3]. Inhibitors are screened targeting on kinases for molecular cancer therapy [4]. In HCC, sorafenib is demonstrated to be the only effective small inhibitor for patients at advanced stage [5]. It still remains a critical challenge to identify relevant molecular targets and effective small inhibitors in liver cancer therapy.

The human monopolar spindle 1 (hMps1/TTK) gene (NM_003318) locates on chromosome 6q13-q21 and encodes a dual serine / threonine and tyrosine protein kinase. TTK is essential for the mitotic checkpoint and improper chromosome attachments [6, 7]. Elevated TTK level leads to amplified centrosomes, hyperactivated SAC and chromosome instability, thus contributing to tumorigenesis [8]. Potential diagnostic value of TTK in certain carcinomas including undifferentiated thyroid carcinoma, triple-negative breast cancer and lung cancer was observed [9-11]. Specific inhibitors of TTK were screened using high throughput in vitro kinase assays, yielding AZ3146, MPI-0479605 and 
Mps1-IN-1 in inhibiting proliferation of cervical carcinoma cell Hela and colon carcinoma cell HCT-116, respectively [12-14]. In HCC, TTK is overexpressed and correlated with age, $\mathrm{HBsAg}$, Edmondson tumour grade and satellite lesion $[15,16]$. However, its role and molecular mechanism still need more investigation.

In this study, we first investigated the clinical significance and prognostic value of TTK in HCC. Exploration of the methylation status of TTK promoter revealed the potential mechanism of its up-regulation in HCC specimens. We then examined its effects on cell proliferation and migration. In addition, we attempted to inhibit HCC cell growth using TTK specific inhibitor. Finally, we explored the signaling pathways activated by TTK in HCC. Our study highlights the significance and underlying mechanism of TTK in HCC carcinogenesis.

\section{RESULTS}

\section{TTK mRNA expression is frequently increased in $\mathrm{HCC}$}

We first assessed the TTK expression profile in several human tissues by RT-PCR and demonstrated that TTK was predominantly expressed in the testis, with very low levels in the ovarian and the small intestine. Notably, TTK was highly expressed in fetal liver while absent in normal human liver (Figure 1A). In 20 cases of HCC tumor specimens, TTK mRNA expressions were dramatically increased, comparison to their paired adjacent non-tumor specimens (Figure 1B). To confirm this result, TTK mRNA level was examined in all 152 patients with HCC by QuantiGene Plex 2.0 $0^{\circledR}$ assay. Compared with the corresponding non-cancerous livers, 118 of the $152 \mathrm{HCC}$ cases $(77.63 \%)$ showed an over 5 -folds increase of the TTK mRNA level $(P<0.001$, Figure 1C).

We then assessed whether the TTK mRNA level was associated with clinical annotations. As shown in Table 1, high expression of TTK was significantly correlated with high level of serum AFP $(P=0.050)$, large tumor size $(P=0.006)$, advanced TNM-stage $(P=0.020)$, more presence of portal vein tumor thrombus (PVTT, $P=0.003$ ) and distant metastasis $(P=0.004)$, which indicates the important role of TTK in HCC tumor growth and metastasis.

We compared the TTK mRNA level in HCC specimens with the serum AFP protein level and found they were not totally consistant. TTK was significantly overexpressed in 30 cases of HCC specimens (30/152, $19.74 \%$ ) with negative serum AFP protein level $(<200 \mu \mathrm{g} / \mathrm{l})$. Considering the original proportion of cases $(84 / 152,55.26 \%)$ with positive serum AFP level $(\geq 200 \mu \mathrm{g} / \mathrm{l})$, the combined use of TTK with AFP would improve the sensitivity of diagnosis up to $75 \%$ (Figure 1D). Interestingly, TTK expression was notably increased in persons under age 50 (Table $1, P=0.001$ ).
In the age segmentation of under 50, the combined use of TTK and serum AFP would improve the diagnostic rate from $61.33 \%$ to $85.33 \%$ (supplymentary Table 1 ). These data suggest that TTK might be a novel biomarker of HCC especially in patients under age 50 .

We then assessed the prognostic value of TTK by analyzing the disease-free survival rate and the overall survival rate. We found that high TTK expression was significantly associated in Kaplan-Meier analysis model with poor disease-free survival rate $(P=0.033$, Figure 1E) and overall survival rate $(P=0.018$, Figure $1 \mathrm{~F})$. Taken together, these results imply that TTK might be a potential marker in diagnosis and prognosis.

\section{Demethylation of TTK promoter contributes to its overexpression in $\mathrm{HCC}$}

TTK mRNA expression is reported to be up-regulated due to copy number variation (CNV) in triple-negative breast cancer [11]. However, considering the frequent deletion of chromosome 6q in HCC [17], we speculates whether epigenetic modifications contribute to the dysregulation of TTK in HCC. Several types of HCC cell lines were treated with demethylating agent 5-aza-2'-deoxycytidine (decitabine, DAC) at a working concentration of $2 \mu \mathrm{M}$ for $72 \mathrm{~h}$. Compared with the no drug treated control, TTK mRNA level increased dramatically in YY-8103, BEL-7404, PLC/PRF/5 and Huh7 cell lines, while it was not observed in only QGY-7701 (Figure 2A).

To confirm the demethylation status of TTK promoter, bisulfite sequencing was conducted in 3 pairs of HCC tumor and non tumor specimens. An elevated TTK expression was observed in these 3 cases of HCC tumor specimens. The sequencing data showed that in all 3 cases of HCC specimens, the amount of the 5-methylcytosine $(5-\mathrm{mC})$ was significantly decreased than in their paired non-cancerous liver tissues $(P<0.001$, Figure 2B).

\section{TTK stimulates HCC cell proliferation, colony formation and migration in vitro}

To evaluate the function of TTK on tumorigenesis in HCC, we then observed the effects of TTK on cell proliferation and anchorage-independent cell growth. Ectopic TTK expression vectors were transfected into BEL-7404 and SMMC-7721 cells. The exogenous expression was validated by western blotting. Cells grew significantly faster than those transfected with the empty control vectors (Figure 3A and 3B). Given that anchorageindependent growth is one of the key hallmarks of cell transformation and malignancy [18], colony formation in soft agar assay was performed. The results demonstrated that exogenous TTK expression stimulated anchorageindependent cell growth $(P<0.05$, Figure 3C and 3D).

To confirm the effects of TTK on HCC cell growth, knockdown experiments were then performed in QGY-7703 
A

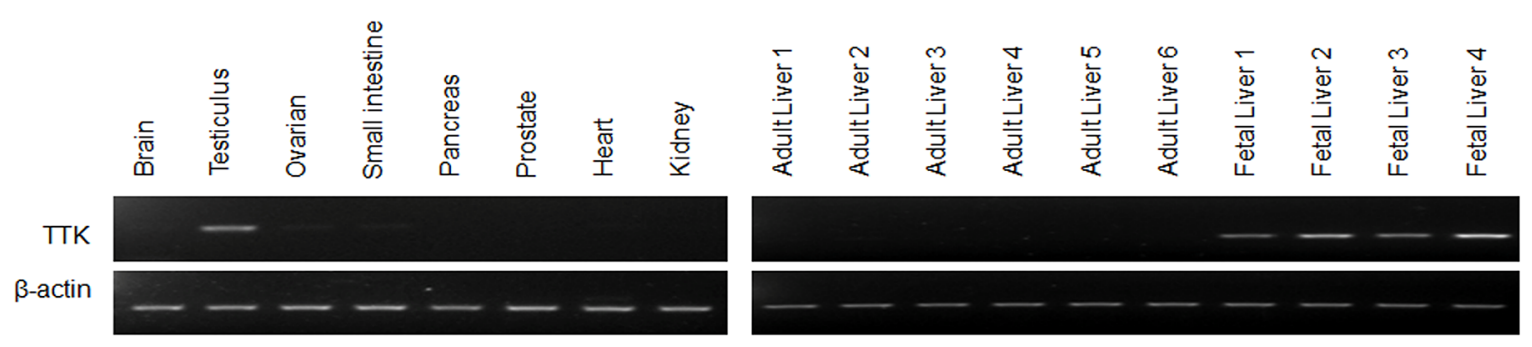

B

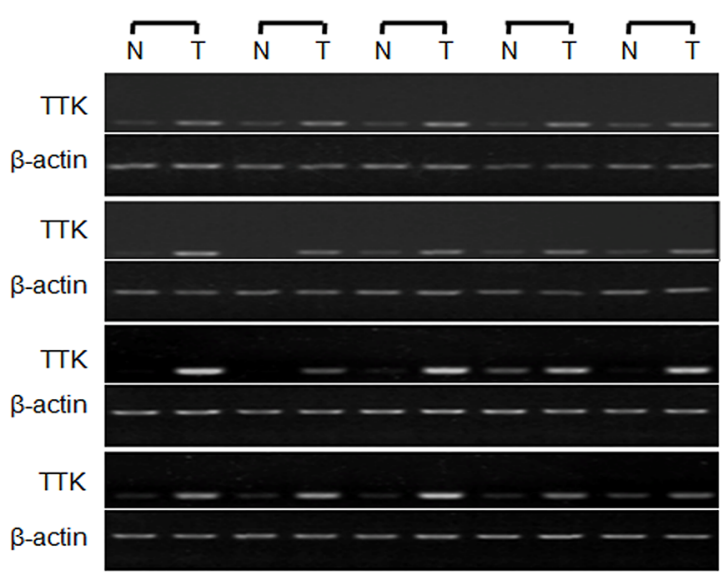

C

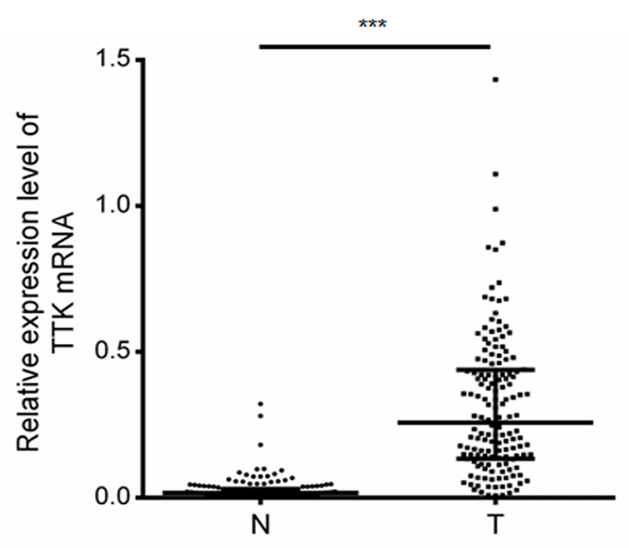

D

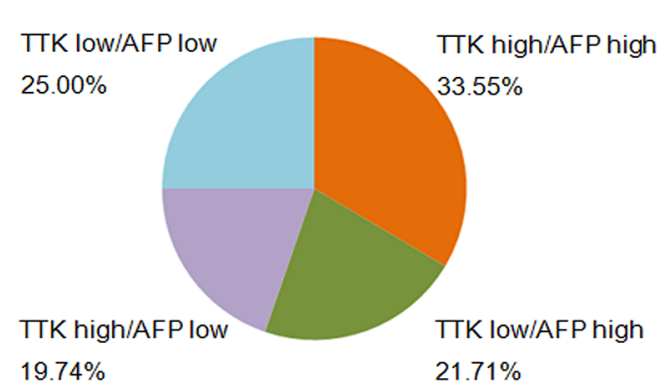

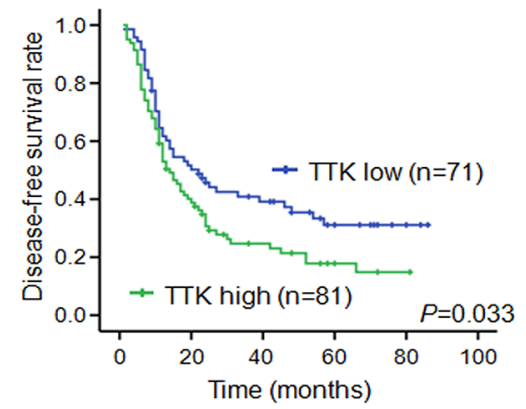

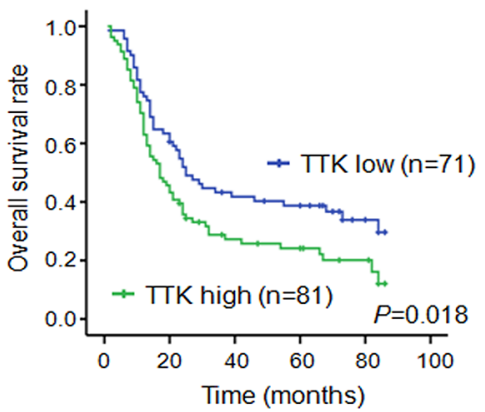

Figure 1: TTK expression patterns and clinical significance of TTK mRNA level in HCC specimens. A. Results of the semi-quantitative RT-PCR analyses of TTK in 8 normal tissues, 6 normal liver tissues and 4 fetal liver tissues. B. Representitive results of TTK mRNA level in 20 pairs of HCC specimens (T) and their adjacent non-tumorous liver tissues (N) C. TTK mRNA level in 152 paired HCC (T) and adjacent non-tumorous liver tissues $(\mathrm{N})$ measured by QuantiGene Plex assay (***, $P<0.001)$. The lines represented 75\%, medium and $25 \%$ of TTK mRNA value, from the top down, respectively. D. The pie chart showed the percentages of the 4 groups divided on the basis of TTK and AFP expression levels in 152 HCC specimens. TTK high: TTK mRNA level is greater than or equal to 0.226 in HCC specimens; TTK low: TTK mRNA level is less than 0.226 in HCC specimens; AFP high: AFP protein level is greater than or equal to $200 \mu \mathrm{g} / \mathrm{l}$ in peripheral blood; AFP low: AFP protein level is less than $200 \mu \mathrm{g} / \mathrm{l}$ in peripheral blood. E. Disease-free survival rates of HCC patients with different TTK expression levels. F. Overall survival rates of HCC patients with different TTK expression levels.

and SMMC-7721 cells. The knockdown efficiency of the designed siRNA was measured by quantitative real-time PCR, with NC-siRNA served as a control. Our data showed that decreased TTK expression inhibited both anchoragedependent (Figure 3E and 3F) and anchorage-independent HCC cell proliferation $(P<0.05$, Figure $3 \mathrm{G}$ and $3 \mathrm{H})$.

We further evaluated whether TTK induced HCC cell migration with transwell assay. BEL-7404 and SMMC-7721 cells with an ectopic TTK expression migrated faster than controls $(P<0.05$, Figure 4A and 4B). On the contrary, transfection of TTK siRNA in QGY-7703 and SMMC-7721 significantly decreased cell migration $(P<0.05$, Figure 4C and 4D). All results suggest that TTK contributes to tumorigenesis through promoting cell growth, colony formation and migration of the existing HCC cells.

\section{TTK activates Akt mediated pathways in HCC cells}

To investigate the underlying mechanism of TTK in stimulating HCC cell proliferation, we first 
Table 1: Correlation between the clinicopathologic variables and TTK expression in HCC

\begin{tabular}{|c|c|c|c|c|c|c|}
\hline \multirow{2}{*}{ Clinical character } & \multirow{2}{*}{ variable } & \multirow{2}{*}{ No. of patients } & \multicolumn{2}{|c|}{ mRNA } & \multirow{2}{*}{$\chi^{2}$} & \multirow{2}{*}{$P$ value } \\
\hline & & & low $n(\%)$ & high $^{\text {a }} n(\%)$ & & \\
\hline \multirow[t]{2}{*}{ Age (years) } & $<50$ & 75 & $25(33.3)$ & $50(66.7)$ & 10.644 & 0.001 \\
\hline & $\geq 50$ & 77 & $46(59.7)$ & $31(40.3)$ & & \\
\hline \multirow[t]{2}{*}{ Gender } & Male & 136 & $60(44.1)$ & $76(55.9)$ & 0.490 & 0.070 \\
\hline & Female & 16 & $11(68.8)$ & $5(31.2)$ & & \\
\hline \multirow[t]{2}{*}{ Family history } & No & 129 & $58(45.0)$ & $71(55.0)$ & 1.048 & 0.367 \\
\hline & Yes & 23 & $13(56.5)$ & $10(43.5)$ & & \\
\hline \multirow[t]{2}{*}{$\mathrm{HbsAg}^{\mathrm{b}}$} & Negative & 32 & $15(46.9)$ & $17(53.1)$ & 0.000 & 1.000 \\
\hline & Positive & 120 & $56(46.7)$ & $64(53.3)$ & & \\
\hline \multirow[t]{2}{*}{$\operatorname{AFP}^{\mathrm{c}}(\mu \mathrm{g} / \mathrm{l})$} & $<200$ & 68 & $38(55.9)$ & $30(44.1)$ & 4.158 & 0.050 \\
\hline & $\geq 200$ & 84 & $33(39.3)$ & $51(60.1)$ & & \\
\hline \multirow[t]{2}{*}{ Median size $(\mathrm{cm})$} & $<3$ & 28 & $14(77.8)$ & $4(22.2)$ & 7.917 & 0.006 \\
\hline & $\geq 3$ & 134 & $57(42.5)$ & $77(57.5)$ & & \\
\hline \multirow[t]{2}{*}{ Cirrhosis } & No & 19 & $5(26.3)$ & $14(73.7)$ & 3.628 & 0.084 \\
\hline & Yes & 133 & 66 (49.6) & $67(50.4)$ & & \\
\hline \multirow[t]{2}{*}{ Tumor number } & Single & 101 & 44 (43.6) & $57(56.4)$ & 1.197 & 0.304 \\
\hline & Multiple & 51 & $27(52.9)$ & $24(47.1)$ & & \\
\hline \multirow[t]{2}{*}{ Wine-drinking } & No & 63 & $24(38.1)$ & $39(61.9)$ & 3.208 & 0.099 \\
\hline & Yes & 89 & $47(52.8)$ & $32(47.2)$ & & \\
\hline \multirow[t]{2}{*}{ Smoking } & No & 67 & $32(47.8)$ & $35(52.5)$ & 0.909 & 0.635 \\
\hline & Yes & 85 & $39(45.9)$ & $46(54.1)$ & & \\
\hline \multirow[t]{2}{*}{ TNM stage $^{\mathrm{d}}$} & I-II & 61 & $36(59.0)$ & $25(41.0)$ & 6.199 & 0.020 \\
\hline & III-IV & 91 & $35(38.5)$ & $56(61.5)$ & & \\
\hline \multirow[t]{2}{*}{ PVTT } & No & 111 & $60(54.1)$ & $51(45.9)$ & 8.915 & 0.003 \\
\hline & Yes & 41 & $11(26.8)$ & $30(73.2)$ & & \\
\hline \multirow[t]{2}{*}{ Distant metastasis } & No & 136 & $69(50.7)$ & $67(49.3)$ & 8.408 & 0.004 \\
\hline & Yes & 16 & $2(12.5)$ & $14(87.5)$ & & \\
\hline \multirow[t]{2}{*}{ Recurrence } & No & 111 & $51(45.9)$ & $60(54.1)$ & 0.097 & 0.855 \\
\hline & Yes & 41 & $20(48.8)$ & $21(51.2)$ & & \\
\hline
\end{tabular}

ahigh of TTK mRNA expression in HCC specimens was designed as greater than or equal to 0.226

${ }^{b} \mathrm{HBsAg}$, hepatitis B surface antigen

${ }^{\mathrm{c}} \mathrm{AFP}$, alpha-fetoprotein

${ }^{\mathrm{d}} \mathrm{TNM}$, tumor-node-metastasis

estimated its effects on activating Akt and mTOR kinases, the signaling pathways contributing to cell growth and anchorage-independent colony formation. Using western blotting, we found that phosphorylation levels of Akt (P-Ser473) and mTOR (P-Thr2446) kinases were significantly increased in BEL-7404 cells with TTK exogenous expression (Figure 5A). We then assessed the phosphorylation levels of Akt downstream protein kinases MDM2 (P-Ser166) and p53 (P-Ser6), key regulators of the cell apoptosis signaling pathway. The phosphorylation of MDM2 was markedly enhanced, whereas the phosphorylation of p53 was 
A

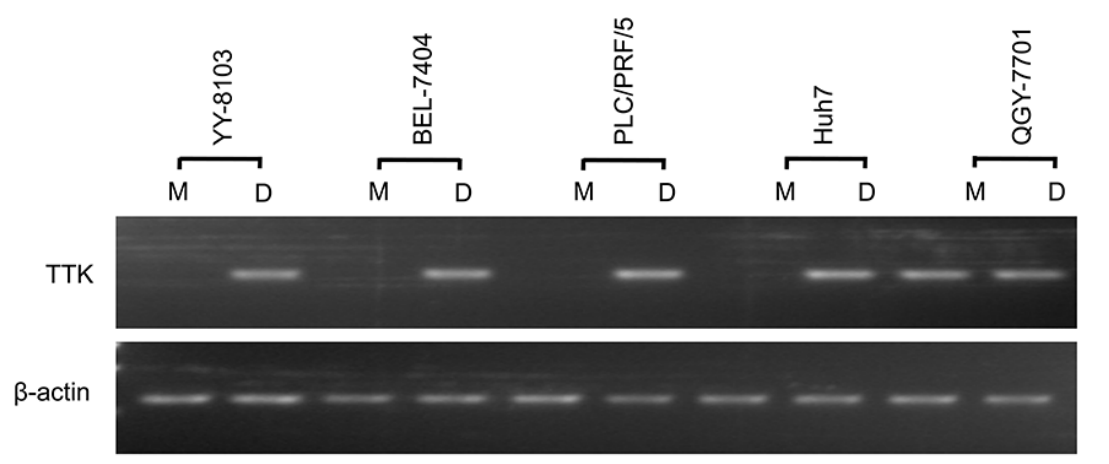

B

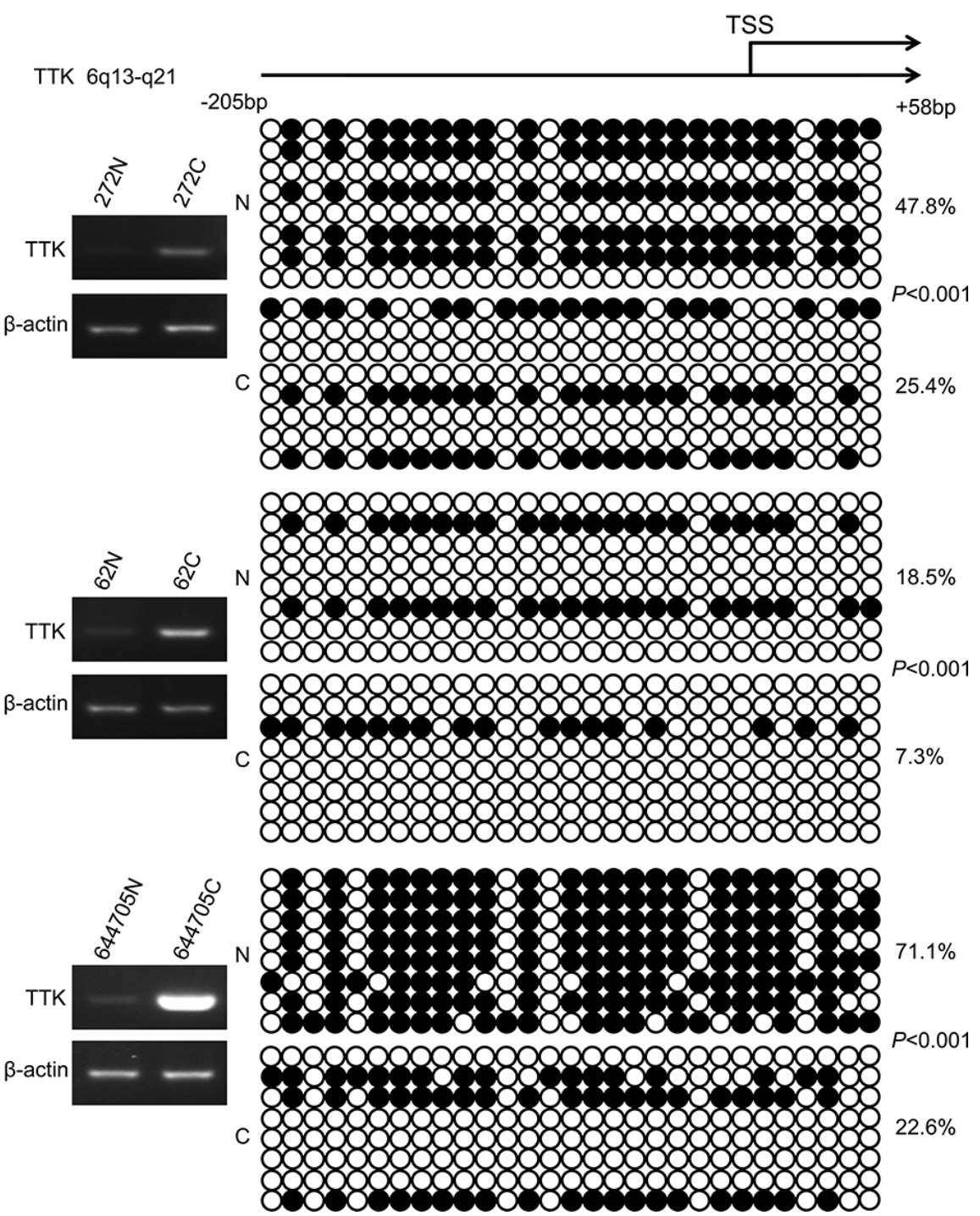

Figure 2: The DNA methylation status of TTK promoters in HCC. A. YY-8103, BEL-7404, PLC/PRF/5, Huh7 and QGY-7701 cells were treated with DAC (work concentration: $2.0 \mu \mathrm{M}$ ). The expression of TTK was evaluated by RT-PCR. M: untreated cells used as control. D: DAC treated cells. B. Results of bisulfite sequencing in 3 cases of HCC specimens with obviously elevated TTK mRNA level. Each circle indicates a $\mathrm{CpG}$ dinucleotide within the $\mathrm{CpG}$ island in the promoter. Black: methylated; white: unmethylated.

significantly suppressed in TTK transfected BEL-7404 cells (Figure 5A). Interestingly, similar activations were not observed in p53 mutant PLC/PRF/5 cells (Figure 5B). It indicates that Akt/mTOR signaling responds differently due to the status of p53. These results demonstrate that TTK stimulates the malignance of $\mathrm{HCC}$ cells via Akt/mTOR and MDM2/p53 activation in a p53 dependent mechanism. 
A
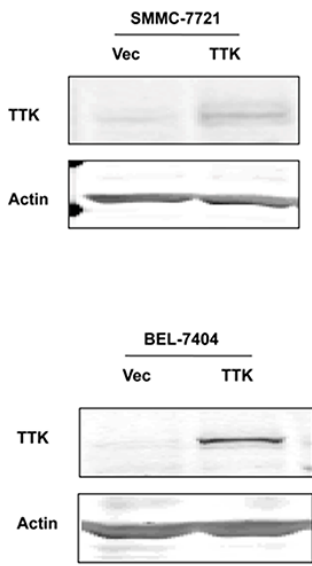

C

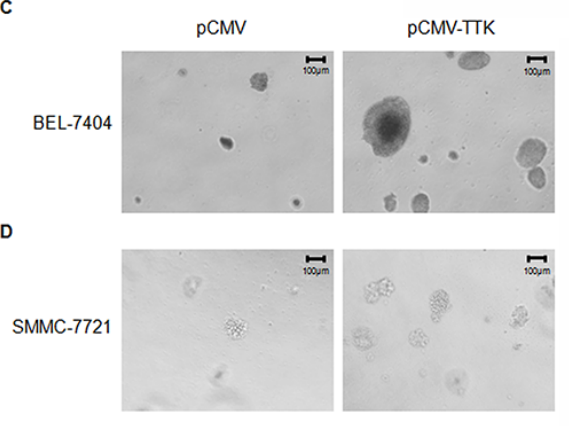

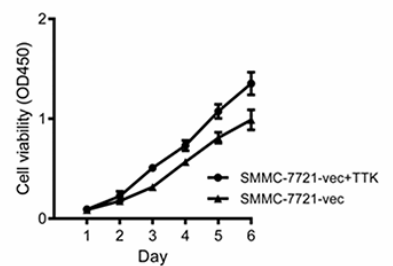

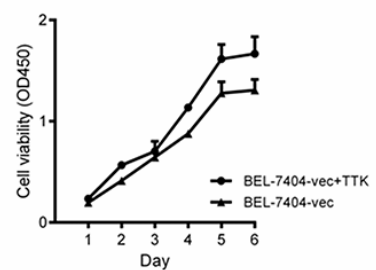

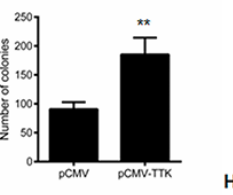

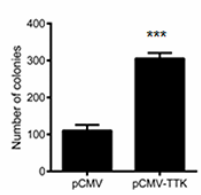

G
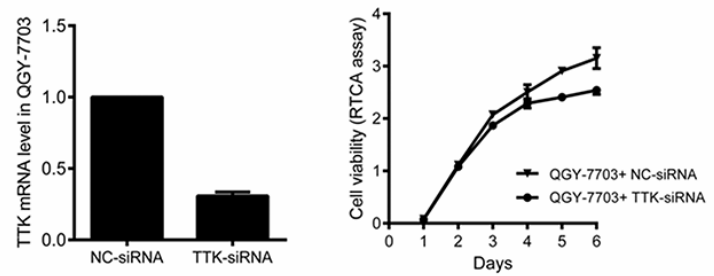

F
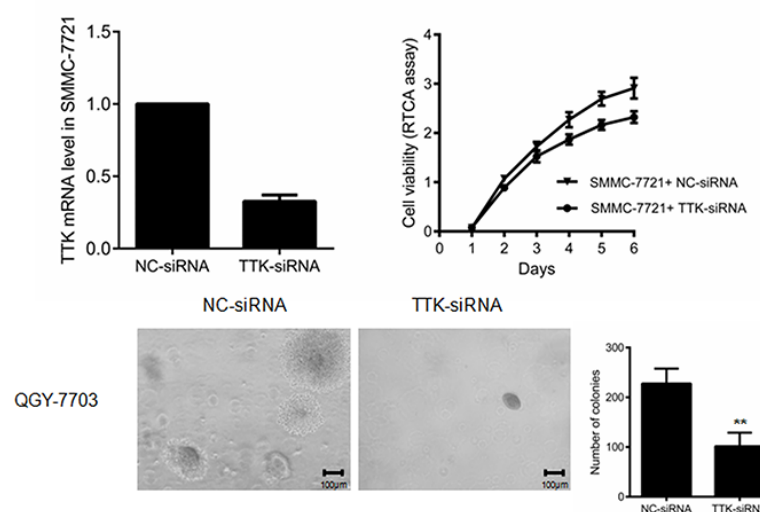

TTK-siRNA
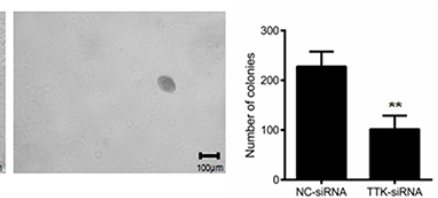

SMMC-7721
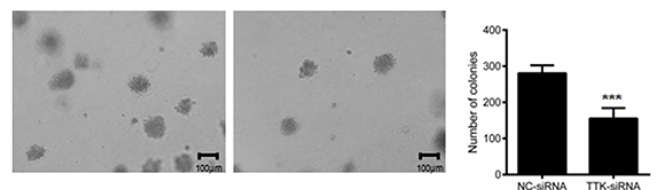

Figure 3: Effects of TTK on HCC cell growth. A. and B. The representative proliferation curve of SMMC-7721 (A) and BEL-7404 (B) after the ectopic expression of TTK. Points, mean $(n=6)$; bars, SD. C. and D. The colony formation in soft agar after the ectopic expression of TTK in BEL-7404 (C) and SMMC-7721 (D) cells. The numbers of colonies in the histograms represented mean values in triplicate (mean $\pm \mathrm{SD})(* *, P<0.01 ; * * *, P<0.001)$. E. and $\mathbf{F}$. The proliferation curves of QGY-7703 (E) and SMMC-7721 (F) after the knockdown of TTK by specific siRNA. Cell proliferation curves were monitered by the RTCA assay. The points represented mean value of 2 times of independent experiments; bars, SD. G. and H. The colony formation in soft agar after the in QGY-7703 (G) and SMMC-7721 (H) cells.

\section{TTK kinase inhibitor AZ3146 impares HCC cell viability}

Based on the results of clinicopathological analyses of TTK, we estimated its potential as a therapeutic target with the specific kinase inhibitor AZ3146. In vitro cell cytotoxicity assays were performed on SMMC-7721 and BEL-7404 cells. The $50 \%$ inhibiting concentration (IC50) values were calculated as being $7.13 \mu \mathrm{M}$ (BEL-7404, Figure 6A) and $28.62 \mu \mathrm{M}$ (SMMC-7721, Figure 6C). Both cells were further treated under the concentration of IC50 for 4 days. Significant inhibitions of cell proliferation were observed (Figure 6B and Figure 6D). The data suggest that TTK serves as a target for AZ3146 in HCC cells.

\section{DISCUSSION}

In this study, we found TTK expression significantly correlated with histologic grade. It indicates that TTK contributed to HCC tumor progression. Screening on various normal tissues revealed that TTK was only expressed highly in the testis. It confirms the similar results identified by Mills et al [19]. Meanwhile, we observed the strong expressions of TTK in human fetal livers and its absence in normal adult human livers. Taken together, we hypothesize TTK as a novel cancer-testis (CT)-related gene. It might contribute to carcinogenesis and tumor progression by hepatocytes de-differentiation to the embryonic state.

According to our data, other clinicopathological characteristics including tumor size, PVTT and distant metastasis were highly associated with TTK. It suggests that TTK stimulates HCC cellular growth and invasion. This hypothesis was convinced by results of in vitro gain and loss of function studies in HCC cells. Furthermore, TTK induced Akt/mTOR and MDM2/p53 signaling pathways with a wild-type p53 background. Considering the anchorage-independent growth ability of cancer cells, it indicates the role of TTK for increasing HCC cell aggressiveness [20]. In melanoma cells, TTK activates Akt and forms an auto-regulatory negative feedback loop with $\mathrm{B}-\mathrm{Raf}^{\mathrm{WT}} / \mathrm{ERK}$ signaling [8]. Besides Akt, TTK involves in several other signaling pathways. Activated TTK promotes TGF- $\beta$-independent Smad signaling activity through 
A
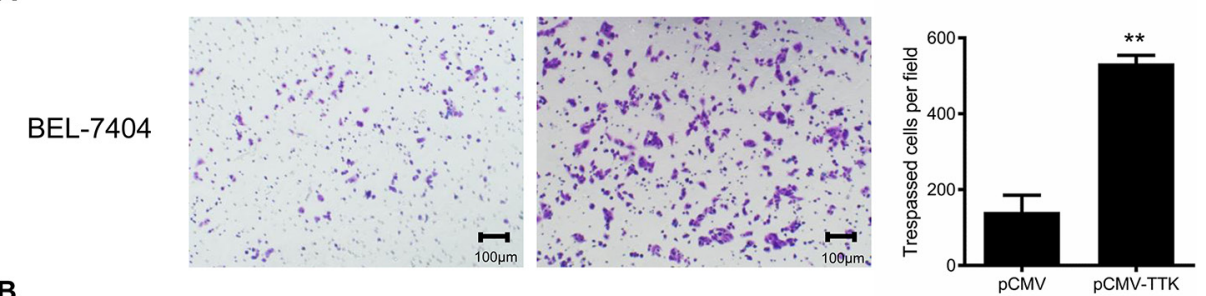

B
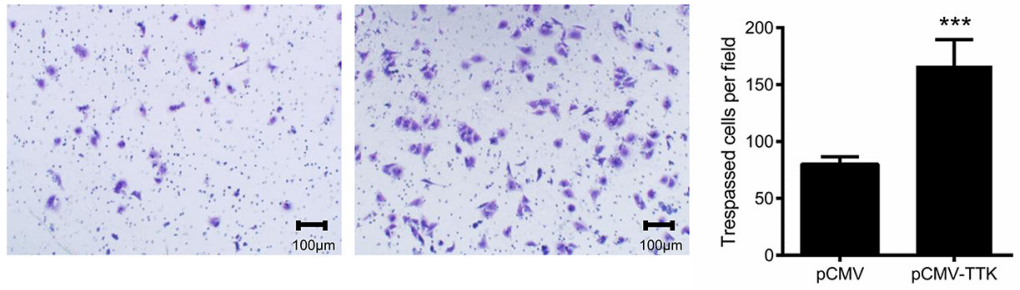

C

NC-siRNA

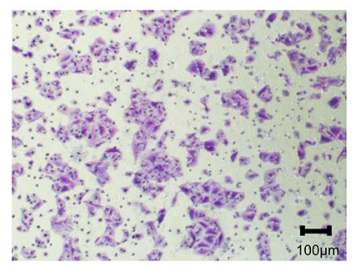

D

SMMC-7721
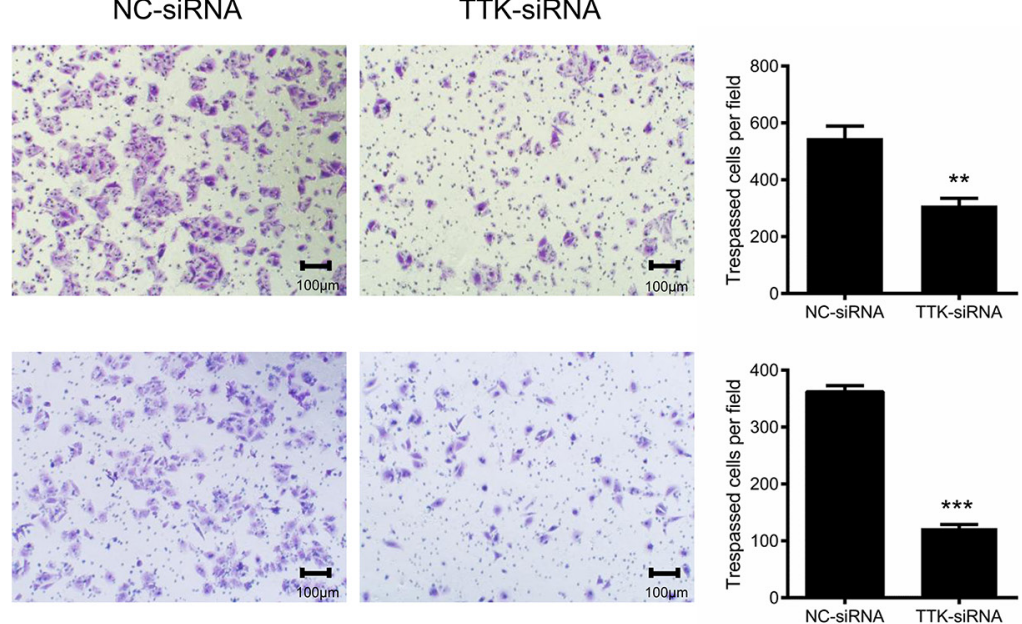

Figure 4: Effects of TTK on HCC cell migration. Representative images of HCC cell migration in transwell assay. A. and B. Exogenous expression of TTK increased BEL-7404 (A) and SMMC-7721 (B) cell migration. C. and D. Reduction of endogenous TTK expression with specific siRNA decreased QGY-7703 (C) and SMMC-7721 (D) cell migration. The number of tespassed cells in the histograms represented mean values per field (from 3 fields, mean $\pm \mathrm{SD})(* *, P<0.01 ; * * *, P<0.001$ ).

phosphorylating Smad2 and Smad3 [21]. Conversely, TTK functions at a point upstream of the MAPK and inhibits the Fus3 activation [22]. Whether TTK functions through these signaling pathways in $\mathrm{HCC}$ still needs more investigations.

Previous studies have revealed the correlation between CNV and the mRNA level of TTK in TNBC [11]. Despite of genetic alterations, aberrant methylation is another major mechanism for the dysregulation of oncogenes [23]. However, whether epigenetic alterations in cancer stimulate TTK expression is still unclear. Here we found the significant demethylation in TTK promoter of the HCC specimens. It demonstrats that epigenetic mechanism at least partly, induces TTK overexpression in liver cancer.

In our research, both TTK depletion and TTK activity inhibition significantly suppressed the viability of HCC cells. This finding strongly supports the data from Liang et al., in which TTK silencing restrains HCC cells resistance to Sorafinib [15]. The results exhibit the therapeutic potential of TTK in HCC treatment.

In conclusion, our data suggest the essential role of TTK in HCC carcinogenesis by promoting cell proliferation and migration, via activation of Akt/mTOR and MDM2/p53 signaling pathways. As a potential oncogene, TTK might serve as a prognostic marker and a therapeutic target valuable for HCC treatment.

\section{MATERIALS AND METHODS}

\section{Tissue specimens and cell culture}

All 152 HCC specimens and their adjacent normal liver specimens were obtained from patients underwent surgical operation at the Affiliated Hospital of Guilin Medical University in China. The diagnoses were described in our perivous study [24]. The pathological evaluations of the tissues were judged according to 
A

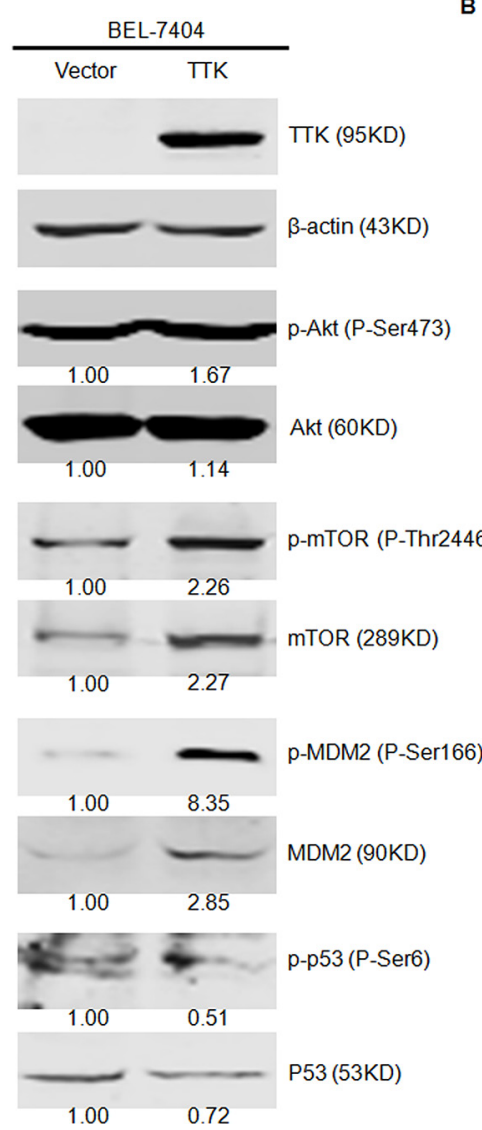

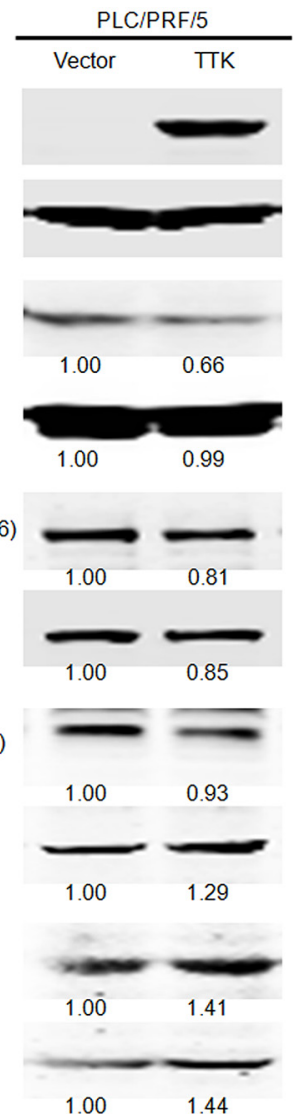

Figure 5: TTK overexpression induces the phosphorylation of Akt relative signaling pathways. A. Overexpression of TTK enhanced the phosphorylation of Akt (P-Ser473), mTOR (P-Thr2446), and MDM2 (P-Ser166) and inhibited the phosphorylation of TP53 (P-Ser6) in SMMC7721 cell line. B. Overexpression of TTK did not enhance the phosphorylation of Akt (P-Ser473), mTOR (P-Thr2446) and MDM2 (P-Ser166) and promoted the phosphorylation of TP53 (P-Ser6) in PLC/PRF/5 cell line. Quantification of each band was normalized to $\beta$-actin and indicated by the numbers above the corresponding panels.
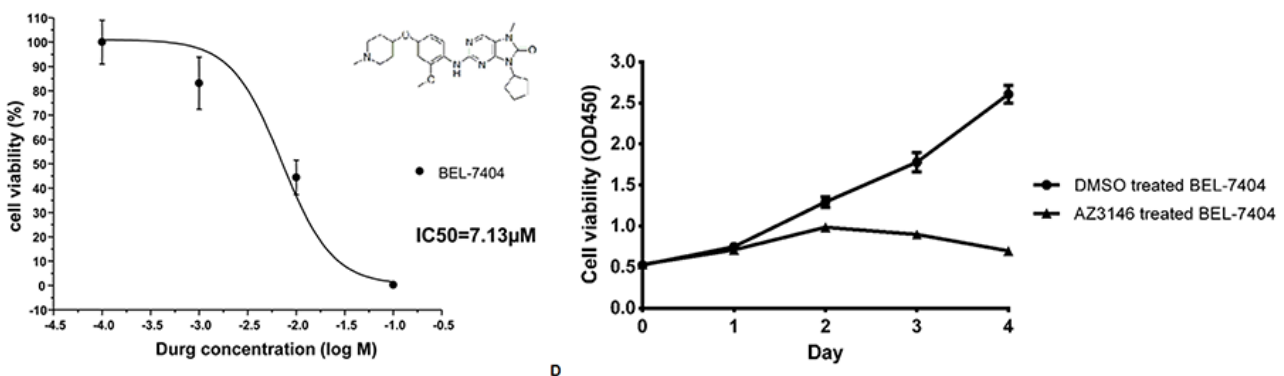

C

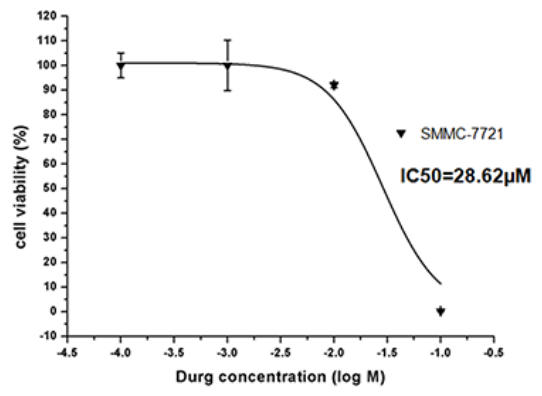

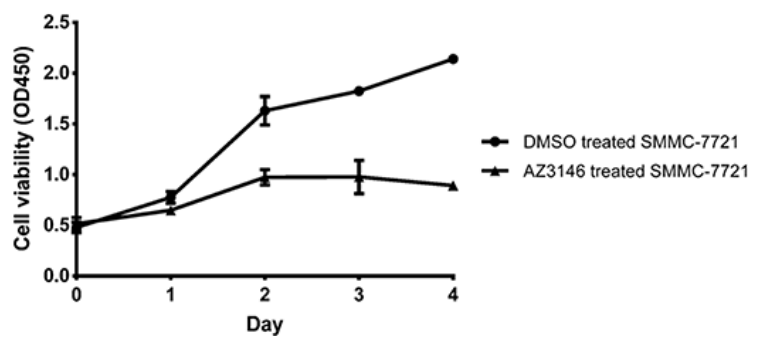

Figure 6: AZ3146 inhibits HCC cell growth in vitro. A. and C. Dose response curve in BEL-7404 (A) and SMMC-7721 (C) with IC50 values, respectively. The molecular structure of AZ3146 was displayed in Figure 6A. B. and D. The growth curve of BEL-7404 (B) and SMMC-7721 (D) under the treatment of AZ3146 at the concentration of their IC50, respectively. Points, mean $(n=6)$; bars, SD. 
"Primary Liver Cancer Clinical Diagnosis and Staging Criteria" [25]. Six specimens of normal liver tissues surrounding the hepatic hemangioma tissues were collected. All of the normal tissues were verified by pathology after the operations. In addition, four cases of fetal tissues were taken from educed fetuses in the Department of Obstetrics in the Affiliated Hospital of Guilin Medical University in China. All of the samples above were frozen in liquid nitrogen and placed at $-80^{\circ} \mathrm{C}$ immediately after the surgical resections. This study was approved by the ethics committee of Hospital Affiliated of Guilin Medical University. All patients provided their written informed consent to participate in this study according to the Declaration of Helsinki.

The following liver tumor-derived cell lines were used in this study: Huh7, SMMC-7721, PLC/PRF/5, YY-8103, QGY-7701, QGY-7703 and BEL-7404. All cell lines were cultured under Dulbecco's Modified Eagle's medium (DMEM; Sigma-Aldrich), supplemented with $10 \%$ FBS (Life Technology) in a $5 \% \mathrm{CO}_{2}$-humidified chamber.

\section{Western blotting}

Total cell proteins were extracted using cell lysate buffer (Cell signaling technology) with 1\% Protease/ Phosphatase Inhibitor Cocktail (Cell signaling technology). Equal amount of proteins were separated by $10 \%$ SDS-PAGE and transferred to nitrocellulose membranes (Amersham, GE Healthcare). Membranes with proteins were blocked by $5 \%$ non-fat milk in PBS buffer and then incubated with primary antibodies overnight at $4{ }^{\circ} \mathrm{C}$. The specific primary antibodies were as follows: Akt antibody (\#C67E7, rabbit monoclonal antibody, dilution 1:1000, Cell Signaling technology), p-Akt (S473) antibody (\#4060, rabbit monoclonal antibody, dilution 1:1000, Cell Signaling technology), mTOR antibody (\#2972, rabbit polyclonal antibody, dilution 1:1000, Cell Signaling technology), p-mTOR (S2481) antibody (\#2974, rabbit polyclonal antibody, dilution 1:1000, Cell Signaling technology), MDM2 antibody (\#YT2690, rabbit polyclonal antibody, dilution 1:1000, ImmunoWay), p-MDM2 (S166) antibody (\#3521, rabbit polyclonal antibody, dilution 1:1000, Cell Signaling technology), p53 antibody (\#9282, rabbit polyclonal antibody, dilution 1:1000, Cell Signaling technology), p-p53 (S6) antibody (\#9285, rabbit polyclonal antibody, dilution 1:1000, Cell Signaling technology), and Flag-tag antibody (\#F3165, mouse monoclonal antibody, dilution 1:1000, Sigma-Aldrich). $\beta$-actin antibody (\#4970, rabbit polyclonal antibody, dilution 1:1000, Cell Signaling technology) was used as the internal positive control. The trace of proteins were scanned after incubated with secondary antibodies conjugated with DyLight fluorescent dyes using Odyssey Infrared Imaging system (LI-COR) and quantitatively measured with Quantity One software.

\section{Semi-quantitative PCR}

Each frozen tissue was cut into pieces of $20-30 \mathrm{mg}$ weight and ground to smash under the liquid nitrogen before RNA extraction. Total RNA was extracted using Trizol reagent (Takara), according to the recommended manual. The concentrations of total RNA were measured using NanoDrop 2000 (Thermo).

Reverse transcription was performed with $1 \mu \mathrm{g}$ Total RNA using PrimeScript ${ }^{\text {TM }}$ RT-PCR Kit (Takara), following the manufacturer's protocal to prevent the genomic DNA contamination.

Semi-quantitative PCR was performed
using the following primers for TTK: 5'-TCCCCAGCGCAGCTTTCTGTAGA-3' (forward) and 5'- CCAGTCCTCTGGGTTGTTTGCCAT-3' (reverse). $\quad \beta$-actin was measured as the internal reference with the following primers: 5'-AATCGTGCGTGACATTAAGGAG-3' (forward) and 5'- ACTGTGTTGGCGTACAGGTCTT -3'(reverse). Lengths of the amplified sequences were $219 \mathrm{bp}$ (TTK) and 273bp ( $\beta$-actin). The PCR reaction was performed in a volume of $20 \mu \mathrm{l}$ using the TaKaRa PCR Kit. The reactions were performed at $94^{\circ} \mathrm{C}$ for $5 \mathrm{~min}$ followed by 34 cycles (for TTK) or 22 cycles (for $\beta$-actin) of $94^{\circ} \mathrm{C}$ for $30 \mathrm{sec}, 55^{\circ} \mathrm{C}$ for $30 \mathrm{sec}$ and $72^{\circ} \mathrm{C}$ for $30 \mathrm{sec}$. The PCR products were separated on $2 \%$ agarose gels containing ethidium bromide.

\section{mRNA quantitation}

The mRNA expression of TTK in HCC specimens and their adjacent non-tumourous liver tissues were quantified using QuantiGene Plex 2.0 ${ }^{\circledR}$ assay (Affymetrix) following the manufacturer's instructions. All the oligo nucleotide probe sets including capture, label and blocker probes were designed by the manufacturer. For each sample, $200 \mu \mathrm{g}$ extracted total RNA was used at the beginning of the assay. Mean fluorescence intensity (MFI) generated from each specific probe set were captured and quantified using a Luminex instrument (Bio-Rad).

\section{Ectopic expression of TTK and RNAi}

The full length of TTK CDS (2574bp, NM_003318) was amplified by PCR from the cDNA of the liver tumor derived cell line SMMC-7721. The primer sequences were designed as follows: 5'-TAGGATCCGCCACCATGGAATCCGAGG

ATTTAAGT-3' (forward) and
5'-GGCTCGAGTTTTTTTCCCCTTTTTTTTTC-3'

(reverse). The PCR products were cloned into the flagtagged pCMV-3Tag-3 vectors (Agilent Technologies). The reconbinant TTK-pCMV-Flag plasmids were transformed into the competent cell DH5 $\alpha$, and extracted using NucleoSpin Plasmid extraction kit (MACHEREYNAGEL). 
The siRNA against TTK and the negative control (NC) were designed and chemically synthesized (Shanghai GenePharma) as follows: TTK: 5'-GUGGCAGAGAAUUGACAAUTT-3' (sense) and 5'-AUUGUCAAUUCUCUGCCACTT-3' (antisense); NC: 5'-UUCUCCGAACGUGUCACGUTT-3' (sense) and 5'-ACGUGACACGUUCGGAGAATT-3' (antisense). The siRNAs worked at the concentration of $100 \mathrm{nM}$. Both plasmids and siRNAs were transfected into cells using Lipofectamine 2000 transfection reagent (Invitrogen) according to the manufacturer's instruction.

\section{Cell proliferation assay}

The "xCELLigence" system (ACEA Biosciences) and the Cell Counting Kit-8 (CCK-8; Dojindo Laboratories) were both applied to monitor cell growth responses.

In The "xCELLigence" system, a label-free measurement of cells is performed in the RTCADP instrument. The cellular status is displayed as the dimensionless parameter "Cell Index" (CI) [26]. After transfection with plasmids or siRNAs for $24 \mathrm{~h}, \mathrm{HCC}$ cells were stripped and replated into the E-plates at the density of $7.5 \times 10^{3}$ per well. E-plates were then transferred to the RTCA instrument for automated real-time monitoring at standard incubator conditions, with quadruplet read-outs of CI every $60 \mathrm{~min}$ the following 6 days. The experiments were independently repeated 2 times.

For cell viability assessment using CCK-8, $3 \times 10^{3}$ cells per well were seeded into 96-well plates. CCK-8 was applied following the manufacturer's protocal at a 24-hour interval for 3-7 days. The absorbance was measured at $450 \mathrm{~nm}$ as an indicator of cell viability. The experiments were independently repeated 3 times.

\section{Soft agar colony formation assay}

TTK-pCMV-Flag plasmids were transfected into HCC cell lines (empty vector as a control). After 24 hours, the transfected cells were stripped and replated into 24 -well plates containing $1 \%$ base agar and $0.5 \%$ top agar, at the density of $2 \times 10^{3}$ cells per well. Plated cells were incubated at $37^{\circ} \mathrm{C}$ for 21 days with a $100 \mu \mathrm{l}$ culture medium addition every 4-5 days. Colonies were counted and photographed under a microscope (magnification, $\times 40$ ). The experiments were independently repeated 3 times.

\section{Cell migration assay}

Cell migration assay was performed using 24-well Transwells ( $8 \mu \mathrm{m}$ pore size; BD Biosciences). Each well of the lower chamber was filled with $500 \mu \mathrm{l}$ DMEM containing $10 \% \mathrm{FBS}$. HCC cells were starved in serumfree medium overnight. A total of $1 \times 10^{5} \mathrm{HCC}$ cells in $500 \mu \mathrm{l}$ DMEM containing 1\% FBS were plated into each well of the upper chamber. After an incubation for $48 \mathrm{~h}$, the cells were fixed with $4 \%$ paraformaldehyde for $15 \mathrm{~min}$ and stainned with $0.5 \%$ crystal violet for at least $30 \mathrm{~min}$. Cells remaining in the upper chamber were removed by cotton swabs. Cells on the lower surface of the membrane were counted and photographed for at least 3 random microscopic fields (magnification, $\times 40$ ). The experiments were independently repeated 3 times.

\section{Bisulfite sequencing}

Genomic DNA was extracted from the paired HCC tumor and the adjacent non-tumor specimens using the Dneasy Tissue kit (Qiagen) before being treated with the EpiTect Bisulfite Kit (Qiagen) according to the manufacturer's instructions. The $\mathrm{CpG}$ island of TTK was estimated at the EMBL-EBI Web Server (http://www.ebi. ac.uk/Tools/seqstats/) and amplified with the following primers: 5'-GTTTAAGGTGTATTTTTTAGG-3' (forward) and 5'-AAAAATAAAACCCAAACTCCTTTC-3' (reverse). The products of the PCR were purified and cloned into the pMD18-T vector (TaKaRa). 5-10 colonies of each sample were randomly picked for sequencing.

\section{Inhibitor treatment to $\mathrm{HCC}$ cells}

The TTK inhibitor AZ3146 (Selleck) was disolved in DMSO at a concentration in $100 \mathrm{mM}$ and diluted into $100 \mu \mathrm{M}, 10 \mu \mathrm{M}, 1 \mu \mathrm{M}$ and $0.1 \mu \mathrm{M}$ sequentially with DMEM containing 10\% FBS before use. In vitro cytotoxicity assays were performed as described previously [27]. HCC cells were plated into 96-well plates at the density of $3 \times 10^{3}$ per well. AZ3146 was added in the indicated concentrations the next day. The inhibitor treated cells were cultured and tested at a 24-hour intervals for 3-4 days using CCK-8.

\section{Statistical analysis}

The statistical analyses were performed using SPSS21.0 software. The cut-off value (0.226) was optimized using Medcalc software for defining high and low subgroups following this paper [28]. The correlation analysis was performed using the Chi-squre Test. The survival analysis was performed using the KaplanMeier method with the Log-Rank Test for statistical significance check. The two-tailed Student's $t$-test was used to evaluate the significance of quantitative variables. The IC50 values were calculated with Origin 8.0 software. $P \leq 0.05$ was defined as statistical significance.

\section{CONFLICTS OF INTEREST}

We declare that none of the participating authors have any relationships that may pose any conflict of interest. 


\section{GRANT SUPPORT}

This work was supported by grants from the National High Technology Research and Development Program of China (2012AA02A205), the National Natural Science Foundation of China (81472639 and 81272306), the Shanghai Commission for Science and Technology (11JC1408800, 13431902000), Program of Shenzhen Science Technology and Innovation Committee (JCYJ20130329171031740, CXZZ20130515163643 and JCYJ20120831144704366).

\section{REFERENCES}

1. Bosch FX, Ribes J, Borras J. Epidemiology of primary liver cancer. Semin Liver Dis. 1999; 19:271-285.

2. Schlessinger J. Cell signaling by receptor tyrosine kinases. Cell. 2000; 103:211-225.

3. Yuan Z, Zheng Q, Fan J, Ai KX, Chen J, Huang XY. Expression and prognostic significance of focal adhesion kinase in hepatocellular carcinoma. J Cancer Res Clin Oncol. 2010; 136:1489-1496.

4. Fedorov O, Muller S, Knapp S. The (un)targeted cancer kinome. Nat Chem Biol. 2010; 6:166-169.

5. Llovet JM, Ricci S, Mazzaferro V, Hilgard P, Gane E, Blanc JF, de Oliveira AC, Santoro A, Raoul JL, Forner A, Schwartz M, Porta C, Zeuzem S, Bolondi L, Greten TF, Galle PR, et al. Sorafenib in advanced hepatocellular carcinoma. N Engl J Med. 2008; 359:378-390.

6. Jelluma N, Brenkman AB, van den Broek NJ, Cruijsen CW, van Osch MH, Lens SM, Medema RH, Kops GJ. Mps1 phosphorylates Borealin to control Aurora B activity and chromosome alignment. Cell. 2008; 132:233-246.

7. Liu X, Winey M. The MPS1 family of protein kinases. Annu Rev Biochem. 2012; 81:561-585.

8. Zhang L, Shi R, He C, Cheng C, Song B, Cui H, Zhang Y, Zhao Z, Bi Y, Yang X, Miao X, Guo J, Chen X, Wang J, Li Y, Cheng X, et al. Oncogenic B-Raf(V600E) abrogates the AKT/B-Raf/Mps1 interaction in melanoma cells. Cancer Lett. 2013; 337:125-132.

9. Salvatore G, Nappi TC, Salerno P, Jiang Y, Garbi C, Ugolini C, Miccoli P, Basolo F, Castellone MD, Cirafici AM, Melillo RM, Fusco A, Bittner ML, Santoro M. A cell proliferation and chromosomal instability signature in anaplastic thyroid carcinoma. Cancer Res. 2007; 67:10148-10158.

10. Landi MT, Dracheva $T$, Rotunno M, Figueroa JD, Liu H, Dasgupta A, Mann FE, Fukuoka J, Hames M, Bergen AW, Murphy SE, Yang P, Pesatori AC, Consonni D, Bertazzi PA, Wacholder S, et al. Gene expression signature of cigarette smoking and its role in lung adenocarcinoma development and survival. PLoS One. 2008; 3:e1651.

11. Maire V, Baldeyron C, Richardson M, Tesson B, Vincent-Salomon A, Gravier E, Marty-Prouvost B, De
Koning L, Rigaill G, Dumont A, Gentien D, Barillot E, Roman-Roman S, Depil S, Cruzalegui F, Pierre A, et al. TTK/hMPS1 is an attractive therapeutic target for triplenegative breast cancer. PLoS One. 2013; 8:e63712.

12. Hewitt L, Tighe A, Santaguida S, White AM, Jones CD, Musacchio A, Green S, Taylor SS. Sustained Mps1 activity is required in mitosis to recruit O-Mad2 to the Mad1-C-Mad2 core complex. J Cell Biol. 2010; 190:25-34.

13. Kwiatkowski N, Jelluma N, Filippakopoulos $P$, Soundararajan M, Manak MS, Kwon M, Choi HG, Sim T, Deveraux QL, Rottmann S, Pellman D, Shah JV, Kops GJ, Knapp S, Gray NS. Small-molecule kinase inhibitors provide insight into Mps1 cell cycle function. Nat Chem Biol. 2010; 6:359-368.

14. Wang W, Yang Y, Gao Y, Xu Q, Wang F, Zhu S, Old W, Resing K, Ahn N, Lei M, Liu X. Structural and mechanistic insights into Mps1 kinase activation. J Cell Mol Med. 2009; 13:1679-1694.

15. Liang XD, Dai YC, Li ZY, Gan MF, Zhang SR, Yin P, Lu HS, Cao XQ, Zheng BJ, Bao LF, Wang DD, Zhang LM, Ma SL. Expression and function analysis of mitotic checkpoint genes identifies TTK as a potential therapeutic target for human hepatocellular carcinoma. PLoS One. 2014; 9:e97739.

16. Miao R, Luo H, Zhou H, Li G, Bu D, Yang X, Zhao X, Zhang H, Liu S, Zhong Y, Zou Z, Zhao Y, Yu K, He L, Sang X, Zhong S, et al. Identification of prognostic biomarkers in hepatitis B virus-related hepatocellular carcinoma and stratification by integrative multi-omics analysis. J Hepatol. 2014; 61:840-849.

17. Huang SF, Hsu HC, Cheng YM, Chang TC. Allelic loss at chromosome band 6q14 correlates with favorable prognosis in hepatocellular carcinoma. Cancer Genet Cytogenet. $2000 ; 116: 23-27$.

18. Hanahan D, Weinberg RA. Hallmarks of cancer: the next generation. Cell. 2011; 144:646-674.

19. Mills GB, Schmandt R, McGill M, Amendola A, Hill M, Jacobs K, May C, Rodricks AM, Campbell S, Hogg D. Expression of TTK, a novel human protein kinase, is associated with cell proliferation. J Biol Chem. 1992; 267:16000-16006.

20. Mori S, Chang JT, Andrechek ER, Matsumura N, Baba T, Yao G, Kim JW, Gatza M, Murphy S, Nevins JR. Anchorage-independent cell growth signature identifies tumors with metastatic potential. Oncogene. 2009; 28:2796-2805.

21. Zhu S, Wang W, Clarke DC, Liu X. Activation of Mps1 promotes transforming growth factor-beta-independent Smad signaling. J Biol Chem. 2007; 282:18327-18338.

22. Cappell SD, Baker R, Skowyra D, Dohlman HG. Systematic analysis of essential genes reveals important regulators of $\mathrm{G}$ protein signaling. Mol Cell. 2010; 38:746-757.

23. Huang J, Zhang X, Zhang M, Zhu JD, Zhang YL, Lin Y, Wang KS, Qi XF, Zhang Q, Liu GZ, Yu J, Cui Y, Yang PY, Wang ZQ, Han ZG. Up-regulation of DLK1 as an imprinted 
gene could contribute to human hepatocellular carcinoma. Carcinogenesis. 2007; 28:1094-1103.

24. Liao W, Liu W, Yuan Q, Liu X, Ou Y, He S, Yuan S, Qin L, Chen Q, Nong K, Mei M, Huang J. Silencing of DLGAP5 by siRNA Significantly Inhibits the Proliferation and Invasion of Hepatocellular Carcinoma Cells. PLoS One. 2013; 8:e80789. 25.

25. Verslype C, Rosmorduc O, Rougier P. Hepatocellular carcinoma: ESMO-ESDO Clinical Practice Guidelines for diagnosis, treatment and follow-up. Ann Oncol. 2012; 23:vii41-48.

26. Hellevik T, Pettersen I, Berg V, Winberg JO, Moe BT, Bartnes K, Paulssen RH, Busund LT, Bremnes R, Chalmers A, Martinez-Zubiaurre I. Cancer-associated fibroblasts from human NSCLC survive ablative doses of radiation but their invasive capacity is reduced. Radiat Oncol. 2012; 7:59.

27. Ishiyama $\mathrm{M}$, Tominaga $\mathrm{H}$, Shiga $\mathrm{M}$, Sasamoto K, Ohkura $\mathrm{Y}$, Ueno K. A combined assay of cell viability and in vitro cytotoxicity with a highly water-soluble tetrazolium salt, neutral red and crystal violet. Biol Pharm Bull. 1996; 19:1518-1520.

28. Liao W, Zhang J, Zhu Q, Qin L, Yao W, Lei B, Shi W, Yuan S, Tahir SA, Jin J, He S. Preoperative Neutrophilto-Lymphocyte Ratio as a New Prognostic Marker in Hepatocellular Carcinoma after Curative Resection. Transl Oncol. 2014; 7:248-255. 